\title{
Induction of cell growth arrest and apoptotic cell death in human breast cancer MCF-7 cells by the COX-1 inhibitor FR122047
}

\author{
HYO-SOON JEONG，JUNG-HYUN KIM, HYE YEON CHOI, EUNG-RYOUNG LEE and SSANG-GOO CHO \\ Department of Animal Biotechnology (BK21), Animal Resources Research Center, and RCTCP, \\ Konkuk University, 1 Hwayang-dong, Gwangjin-ku, Seoul 143-701, South Korea
}

Received February 10, 2010; Accepted May 6, 2010

DOI: 10.3892/or_00000866

\begin{abstract}
Non-steroidal anti-inflammatory drugs (NSAIDs), which inhibit the enzyme cyclooxygenase (COX), are known to have a potent anti-tumorigenic activity in various cancers. However, the responsible molecular mechanisms of COX inhibition in breast cancer cells remain to be completely elucidated. We examined the effect of the selective COX-1 inhibitor, FR122047 and the selective COX-2 inhibitor, SC791 on cell growth and apoptosis in human breast cancer MCF-7 cells which exhibited a high basal level of COX-1 expression. Compared to SC791, FR122047 treatment led to a distinct suppression of cell growth in MCF-7 cells. Upon FR122047 treatment, there were apparent increases in the ratio of Bax to $\mathrm{Bcl}-2$, mitochondrial cytochrome $\mathrm{c}$ release, and apoptosis in MCF-7 cells. Our data showed that treatment of caspase- 8 inhibitor could significantly suppress the cleavage of the effector caspase-7 and PARP in FR122047-treated MCF-7 cells which are caspase-3-deficient breast cancer cells, indicating that the induction of apoptosis by FR122047 is significantly dependent on caspase- 8 activity in MCF-7 breast cancer cells. Our data suggest that the NSAID FR122047 may have an anti-cancer potential in breast cancer.
\end{abstract}

\section{Introduction}

Breast cancer is the most frequent malignancy in women globally and the second leading cause of death by cancer in females. Breast cancer cells develop through a multistep process such as hyperplasia, carcinoma in situ, invasive cancer and metastasis (1).

Cyclooxygenase (COX) is the principal enzyme in the synthesis of prostaglandins (PGs) from arachidonic acid and two isoforms of cyclooxygenase, COX-1 and COX-2, have been characterized. COX-1 is constitutively expressed in various tissues, whereas COX-2 is the inducible enzyme in response to certain stimuli including growth factors and proinflammatory cytokines $(2,3)$. Several laboratories demon-

Correspondence to: Dr Ssang-Goo Cho, Department of Animal Biotechnolgy, Konkuk University, 1 Hwayang-dong, Gwangjin-ku, Seoul 143-701, South Korea

E-mail: ssangoo@konkuk.ac.kr

Key words: NSAIDs, COX-1, COX-2, apoptosis, MCF-7 strated that increased expression of COX-2 might be a contributing factor in breast cancer development (4-8). In addition to COX-2, COX-1 may also play a role in mammary carcinogenesis, and a report revealed that $\mathrm{COX}-1$ selective inhibitor as well as COX-2 selective inhibitor led to inhibition of cell growth and metastatic capacity of mammary tumors (9). Actually, non-steroidal anti-inflammatory drugs (NSAIDs), which inhibit the enzyme cyclooxygenase (COX), have received attention because of their effects of prevention and treatment of tumor malignancy $(3,8,10)$. Epidemiological studies have indicated that long-term use of NSAIDs is related to a reduced risk of breast cancer $(11,12)$. In recent years, many reports have shown the anti-cancer activity of NSAIDs including cell cycle arrest, inhibition of cell proliferation, and induction of cell death $(13,14)$. Because COX-2 is highly expressed in tumors and clearly enhances tumorigenesis, the focus has been on the use of COX-2 selective inhibitors in prevention of human cancer. However, much less attention has been paid to a possible role for the COX-1 inhibitors in breast cancer as compared to COX-2 inhibitor.

Apoptosis is the most characterized type of programmed cell death which is dependent on the caspase activity and is triggered by activation of both the mitochondrial (intrinsic) and death receptor (extrinsic) pathways, ultimately leading to cell death with membrane blebbing, cell shrinkage, and chromatin condensation $(15,16)$.

Studies on the molecular mechanism of novel drug action are considerably essential for the development of chemotherapy. FR122047, a selective COX-1 inhibitor was reported to have an analgesic effect in chemical nociceptive models and an anti-inflammatory effect in animal models of chronic inflammtion $(17,18)$ but the anti-cancer activity of the chemical has not yet been identified. Here, we report that exposure of MCF-7 breast cancer cells to FR122047, a COX-1 inhibitor resulted in a dose-dependent cell growth arrest and apoptotic cell death. The compound inhibited the expression of the antiapoptotic protein $\mathrm{Bcl}-2$, resulting in an altered ratio of Bax to Bcl-2. Our data also indicate that FR122047 might activate major apoptosis signaling via caspase-8 activation in MCF-7 cells.

\section{Materials and methods}

Materials and antibodies. FR122047, a selective and potent inhibitor of COX-1 $(17,18)$ and SC791, a selective COX-2 inhibitor $(19,20)$ were purchased from Calbiochem (La Jolla, 
CA, USA). Stock solutions of FR122047 and SC791 were prepared in dimethyl sulfoxide (DMSO) and an equal volume of DMSO was added to the controls. 2',7'-Dichlorodihydrofluorescein diacetate (DCFH-DA) and MitoTracker Red (mitochondrial dye) were from Molecular Probes (Eugene, OR, USA). Electrophoresis reagents and Bio-Rad protein assay kit were purchased from Bio-Rad. N-acetyl-L-cysteine (NAC) was purchased from Sigma (St. Louis, MO, USA). Pancaspase inhibitor (z-VAD-FMK), caspase-8 inhibitor (z-IETD-FMK), and caspase-9 inhibitor (z-LEHD-FMK) were from BD Biosciences (San Diego, CA, USA). Antibodies against Bcl-2, Bcl-xL, Bax, caspase-7, actin, cleaved poly (ADP-ribose) polymerase (PARP), and cytochrome c were obtained from Santa Cruz Biotechnology (Santa Cruz, CA, USA).

Cell culture. Human breast cancer MCF-7 cells (an estrogen receptor-positive cell line derived from an in situ carcinoma) were cultured in DMEM, supplemented with $10 \%$ heatinactivated fetal bovine serum and $100 \mathrm{U} / \mathrm{ml}$ of penicillin/ streptomycin (Life Technologies, Inc., Gaithersburg, MD, USA). MCF-10A cells (a non-tumorigenic epithelial cell line) were cultured in DMEM/F12, supplemented with $15 \mathrm{mM}$ HEPES buffer, $5 \%$ horse serum, $10 \mu \mathrm{g} / \mathrm{ml}$ insulin, $20 \mathrm{ng} / \mathrm{ml}$ EGF, $100 \mathrm{ng} / \mathrm{ml}$ choleratoxin, $0.5 \mu \mathrm{g} / \mathrm{ml}$ hydrocortisone, and penicillin/streptomycin. Cells were maintained under a humidified atmosphere of $5 \% \mathrm{CO}_{2}$ at $37^{\circ} \mathrm{C}$.

RNA isolation and real-time RT-PCR. Total RNA was extracted from the cells using TRIzol reagent (GibcoBRL, Gaithersburg, MD, USA) according to the manufacturer's protocol and the extracted RNA samples were subsequently treated with AMV Reverse transcriptase (Promega, Southampton, UK). Real-time PCRs were performed using specific primers for COX-1: forward, 5'-TAGAGATTGGG GCTCCCTTT-3' and reverse, 5'-AGGGACAGGTCTTGGT GTTG-3'; COX-2: forward, 5'-TGAGCATCTACGGTTTG CTG-3' and reverse, 5'-TGCTTGTCTGGAACAACTGC-3'; and GAPDH: forward, 5'-GGGAAGAGTCAACGGATTT GGTCGT-3' and reverse, 5'-GGGAATTGATTTTGGAGG GATCTCG-3'. Real-time PCRs were performed by a fluorescence detection method using the DNA Engine OPTICON ${ }^{\circledR}$ 2 system (MJ Research, Waltham, MA) and DyNAmo HS SYBR-Green qPCR kit (Finnzymes, Espoo, Finland).

Cell viability assay. Cultured cells were exposed to FR122047 and then their viability was analyzed by trypan blue exclusion assay. Briefly, an aliquot of the cell suspension was diluted $1: 1(\mathrm{v} / \mathrm{v})$ with $0.4 \%$ trypan blue and the cells were counted with a hemocytometer. Results are expressed as the percentage of dead cells (ratio of stained cells vs. the control number of cells).

Flow cytometry analysis. Cells were detached from plates by the addition of $0.25 \%$ trypsin, washed in phosphatebuffered saline (PBS), fixed in $70 \%$ ethanol and stained with propidium iodide (PI) for $15 \mathrm{~min}$ at room temperature in the dark. Analysis of cells with sub-G0/G1 DNA content (subdiploid cells) was performed on 10,000 cells on a FACScan flow cytometer using the CellQuest analysis program (Becton-Dickinson), as described previously (21).

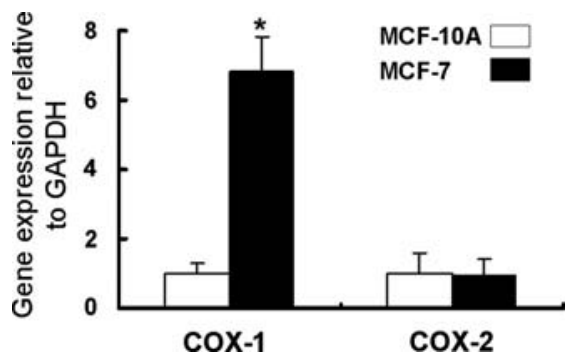

Figure 1. Expression of COX-1 and COX-2 mRNA in human breast normal and cancer cell lines. Total RNA was isolated and the mRNA level of COX-1 or COX-2 was measured by real-time RT-PCR. Expression levels relative to GAPDH are presented. The experiments were repeated independently at least three times. ${ }^{*} \mathrm{P}<0.05$ vs. the control MCF-10A.
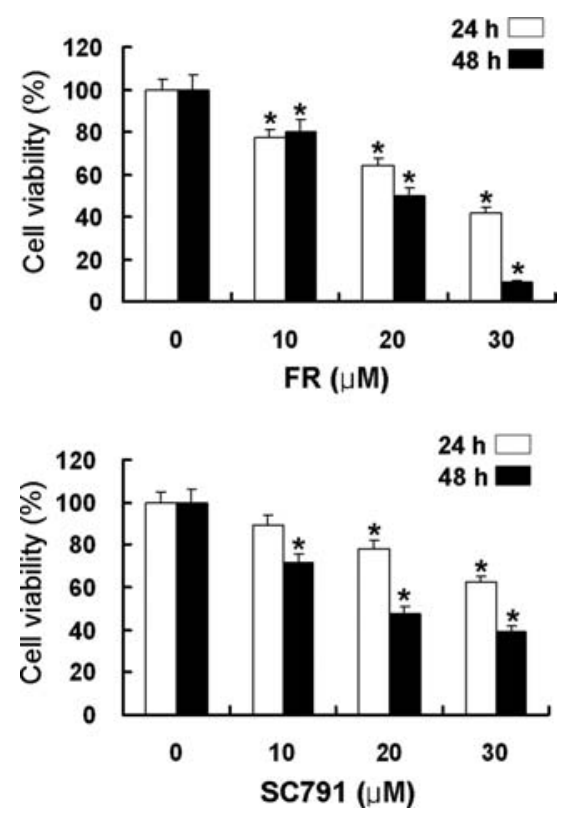

Figure 2. Growth inhibition after exposure to NSAIDs in MCF-7 human breast cancer cells. Cells were exposed to variable concentration of FR122047 (FR) or SC791 for 24 or 48 h. Cell viability of MCF-7 cells following drug treatment was measured by trypan blue exclusion assay. Values represent the mean \pm SE from three independent experiments. ${ }^{*} \mathrm{P}<0.05 \mathrm{vs}$. the control.

Fluorescence microscopy. To investigate mitochondrial cytochrome c release, cells were seeded onto coverslips and allowed to attach overnight. Cells were exposed to $30 \mu \mathrm{M}$ FR122047 for the desired time period at $37^{\circ} \mathrm{C}$, rinsed with PBS, and fixed with $3.7 \%$ paraformaldehyde in PBS for $20 \mathrm{~min}$ at room temperature. Cells were then permeabilized with $0.1 \%$ Triton $\mathrm{X}-100$ for $15 \mathrm{~min}$ at room temperature, washed with PBS, and blocked in PBS containing 5\% normal goat serum for $30 \mathrm{~min}$ at room temperature. Cells were treated with anti-cytochrome c antibody overnight at $4^{\circ} \mathrm{C}$, washed, and then incubated with FITC-conjugated goat anti-mouse secondary antibody for $1 \mathrm{~h}$ at room temperature. After washing with PBS, the cells were counterstained with MitoTracker Red (mitochondrial dye) to localize mitochondria and examined using a confocal microscope (Olympus, Japan).

Detection of intracellular ROS formation. For measurement of intracellular ROS levels, cells were incubated with $10 \mu \mathrm{M}$ 
A
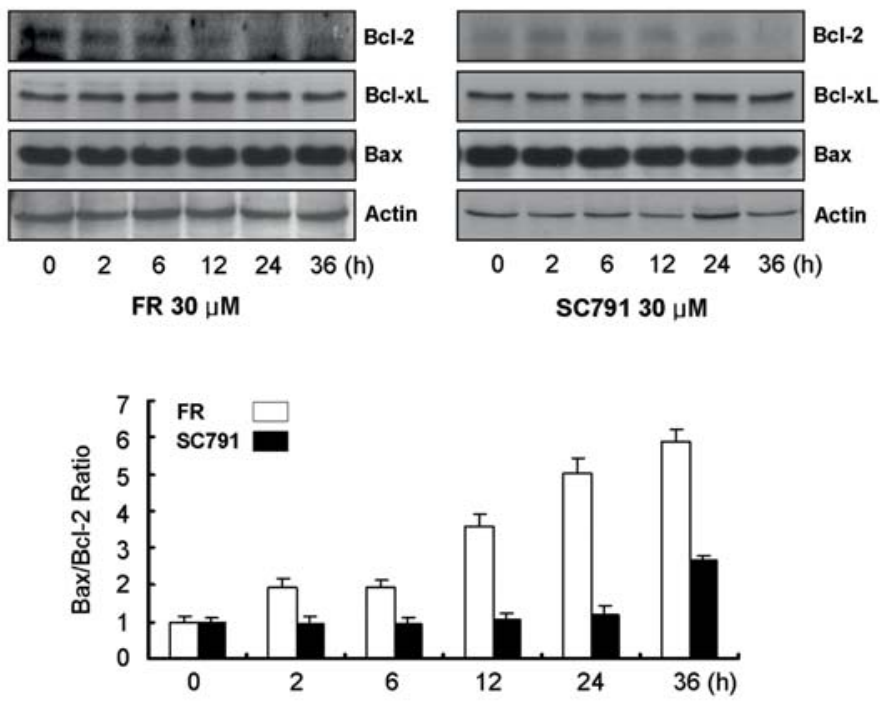

B

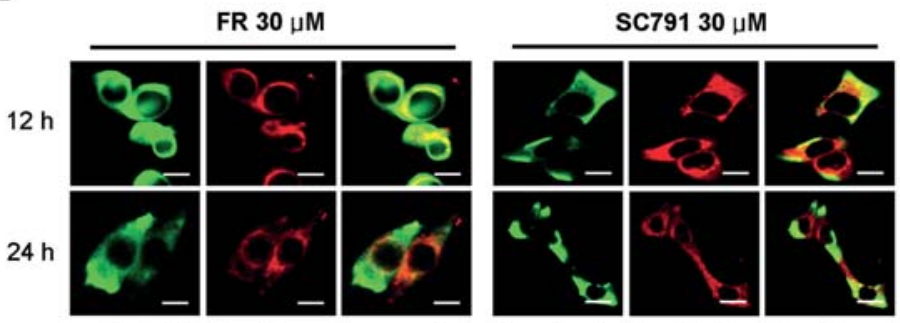

Localization of cytochrome $c$ (green) and mitochondria (red) in cells

Figure 3. Effect of FR122047 and SC791 on expression of Bcl-2 family proteins and release of cytochrome c in MCF-7 cells. (A) Time-course expression of Bcl-2 family members after treatment of FR122047 or SC791. Cells were incubated with $30 \mu \mathrm{M}$ FR122047 (FR) or $30 \mu \mathrm{M}$ SC791 for the indicated time period and lysed. The expression of Bcl-2, Bcl-xL, or Bax was analyzed by Western blotting. Actin was used as loading control. Representative blots from three independent experiments are presented. The bottom panel displays the Bax/Bcl-2 ratio. (B) Immunocytochemical localization of cytochrome $\mathrm{c}$ and mitochondria in FR-treated MCF-7 cells. Cells were treated with $30 \mu \mathrm{M}$ FR or $30 \mu \mathrm{M}$ SC791 for 12 or $24 \mathrm{~h}$, fixed, and stained with cytochrome c antibody (green, left panels) and MitoTracker Red (red, middle panels); overlay of staining patterns is shown in the right panels. Release of cytochrome c from the mitochondria into the cytosol was examined by confocal microscopy. Scale bar represents $10 \mu \mathrm{m}$. Representative images from three different experiments are presented.

DCFH-DA for $30 \mathrm{~min}$ at $37^{\circ} \mathrm{C}$ in the dark, washed and suspended with PBS. Fluorescence-stained cells were analysed by fluorescence-activated cell sorting (FACS; BecktonDickinson FACScan) using CellQuest 3.2 software (BectonDickinson) for acquisition and analysis (22).

Western blot analysis. To prepare whole-cell extracts, cells were washed with ice-cold PBS and lysed in extraction buffer containing $1 \%$ Triton $\mathrm{X}-100,100 \mathrm{mM}$ Tris- $\mathrm{HCl}, \mathrm{pH} 7.5$, $10 \mathrm{mM} \mathrm{NaCl}, 10 \%$ glycerol, $1 \mathrm{mM}$ sodium orthovanadate, $50 \mathrm{mM}$ sodium fluoride, $1 \mathrm{mM}$ p-nitrophenyl phosphate, and $1 \mathrm{mM}$ phenylmethylsulfonyl fluoride. After incubation on ice for $30 \mathrm{~min}$, lysates were centrifuged and protein in the supernatants was quantified using the Bradford Protein Assay Reagent (Bio-Rad). An equal amount of protein was then separated on a 10-15\% SDS-PAGE gel followed by electrophoretic transfer to nitrocellulose membranes and processed for Western blot analysis using appropriate antibody. Specific bands were detected by enhanced chemiluminescence system (Amersham Pharmacia Biotech, Piscataway, NJ, USA) as recommended by the manufacturer. The band density was quantified using NIH ImageJ software.
Statistical analysis. Data were expressed as means \pm SE of three independent tests. The Student's t-test was conducted for testing statistical significance between groups and $\mathrm{P}<0.05$ was considered significant.

\section{Results}

Expression of $\mathrm{COX}-1$ and $\mathrm{COX}-2$ in human breast cancer cells. The levels of COX-1 and COX-2 expression in MCF-10A cells (a non-tumorigenic epithelial cell line) and MCF-7 breast cancer cells were investigated by real-time RT-PCR. A very high basal level of COX-1 expression was observed in MCF-7 cells as compared to MCF-10A (Fig. 1), whereas no differences in the basal level of $\mathrm{COX}-2$ expression were observed in MCF-10A and MCF-7 cells. These data indicate that a high basal level of COX-1 that is known to be constitutively expressed in almost all tissues may be associated with estrogen receptor-positive breast tumors.

Effect of COX-1 inhibitor and COX-2 inhibitor on growth of MCF-7 cells. The inhibitory effect of the COX-1 selective inhibitor FR122047 (FR) and COX-2 selective inhibitor 
A
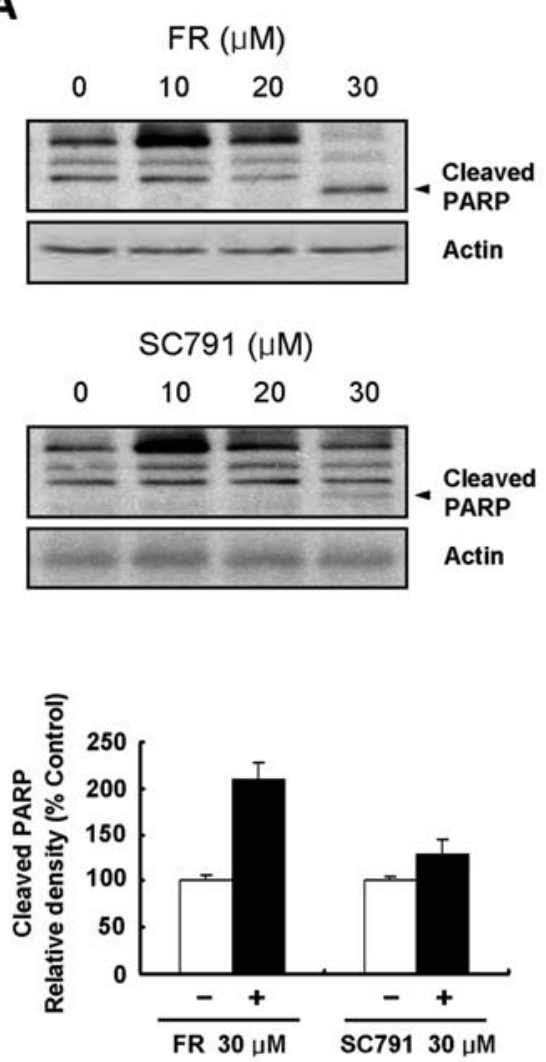

B
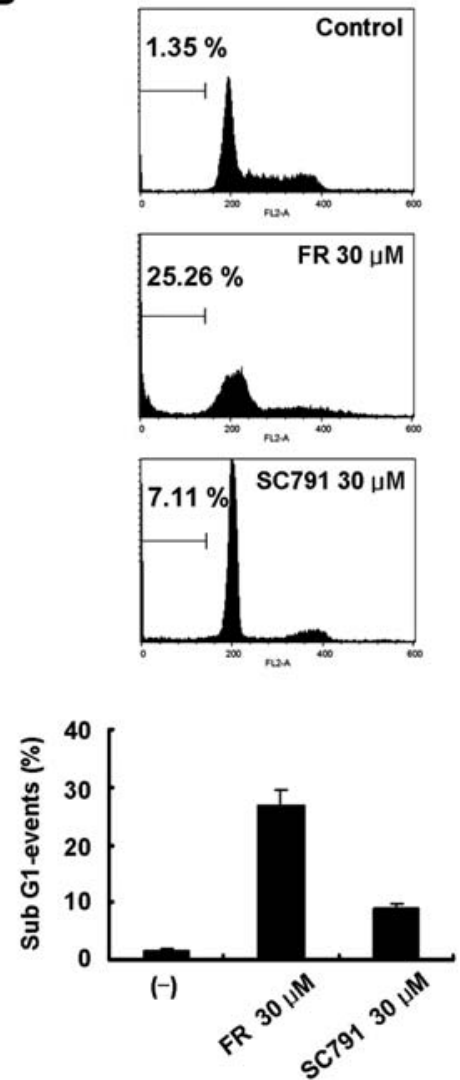

Figure 4. Induction of apoptosis by FR122047 treatment in MCF-7 cells. (A) Cells were treated with the indicated concentration of FR122047 (FR) or SC791 for $24 \mathrm{~h}$, lysed, and proteins were separated by SDS-polyacrylamide gel electrophoresis. Western blot analysis was performed using antibody against cleaved PARP or actin (loading control). Representative data from three different experiments are presented. Bottom panel, results of densitometric analyses of the cleaved PARP levels. Values represent the mean \pm SE from three independent experiments. (B) Percentage of subdiploid cells was determined by flow cytometry after treatment with $30 \mu \mathrm{M}$ FR or $30 \mu \mathrm{M}$ SC791 for $24 \mathrm{~h}$. Representative results of three different experiments are presented.

SC791 on MCF-7 cell growth was first determined using the trypan blue exclusion assay. Both FR and SC791 had a significant dose- and time-dependent inhibitory effect on MCF-7 cell growth (Fig. 2). Treatment of FR exhibited a higher growth inhibitory effect than that of SC791.

Effect of FR122047 and SC791 on the levels of Bcl-2 family and mitochondrial cytochrome c release in MCF-7 cells. Changes in the ratio between pro-apoptotic and anti-apoptotic members of the Bcl-2 family, rather than the expression level of Bcl-2 family member alone, is crucial for drug-induced apoptosis $(23,24)$. Therefore, we first analyzed the expression level of pro-apoptotic and anti-apoptotic members of the Bcl-2 family protein in COX-1 inhibitor FR 122047 (FR)- or COX-2 inhibitor SC791-treated MCF-7 cells. Treatment of MCF-7 cells with FR122047 induced a rapid down-regulation of Bcl-2 with no change in Bcl-xL or Bax, resulting in an increase in the $\mathrm{Bax} / \mathrm{Bcl}-2$ ratio (Fig. $3 \mathrm{~A}$ ). Although MCF-7 cells exposed to SC791 also showed a slight decrease in Bcl-2 level, the change of the Bax/Bcl-2 ratio was just not significant compared to the case with FR122047 treatment (Fig. 3A). We next investigated the effect of FR122047 or SC791 on cytochrome c release by immunocytochemistry. The cytochrome $\mathrm{c}$ in MCF-7 cells treated with FR122047 for $12 \mathrm{~h}$ was mainly localized in mitochondria, as disclosed by a yellow staining due to the merging of mitochondria-associated red fluorescence (MitoTracker Red) and green fluorescence derived from cytochrome $\mathrm{c}$. Treatment of FR122047 for $24 \mathrm{~h}$ caused mitochondrial cytochrome c release to the cytosol in MCF-7 cells, which was evidenced by accumulation of cytochrome c-associated green fluorescence in the cytosol, whereas treatment of MCF-7 cells with SC791 did not trigger significant mitochondrial cytochrome c release.

Effect of FR122047 and SC791 on apoptosis in MCF-7 cells. Compared to SC791-treated cells, we revealed that PARP was more markedly cleaved in FR122047-treated MCF-7 cells (Fig. 4A). Treatment with FR122047 elicited a pronounced increase in the proportion of cells with sub-diploid DNA content but SC791-treated MCF-7 cells had a much lower proportion of cells with subdiploid DNA content (Fig. 4B).

FR122047 induces apoptosis in MCF-7 cells via caspase-8 activation independent of reactive oxygen species (ROS) production. In view of the known relationship between reactive oxygen species (ROS) generation and apoptosis, we examined whether ROS accumulation contributes to apoptosis in FR122047 (FR)-treated MCF-7 cells. MCF-7 cells treated with FR showed accumulation of intracellular ROS, which was abolished by addition of the anti-oxidant Nacetyl-cysteine (NAC) (Fig. 5A). However, treatment with 
A

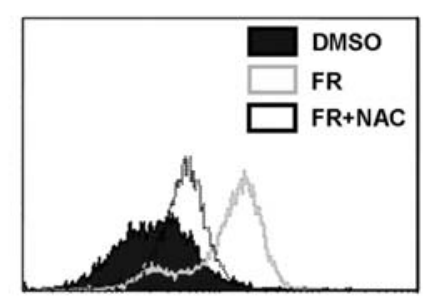

C

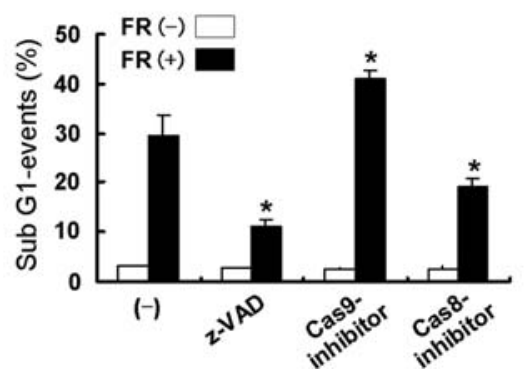

B

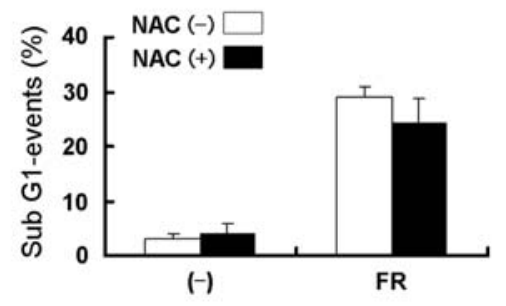

D

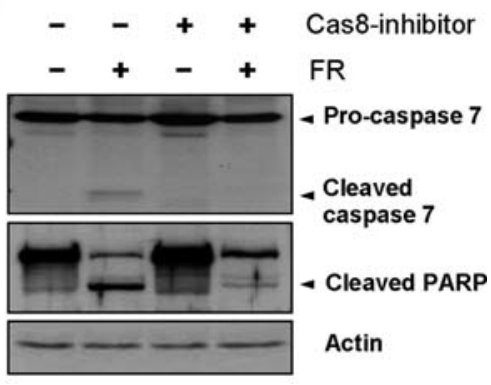

Figure 5. Induction of caspase-8-dependent apoptosis by FR122047 treatment in MCF-7 cells. (A) After treatment with $30 \mu$ M FR122047 (FR) or 2 mM NAC for $12 \mathrm{~h}$, alone or in combination, cells were stained with the fluorescent probe DCFH-DA and intracellular ROS levels were measured by FACS analysis. Increased ROS level is indicated by an increase in fluorescence and shift of the curve to the right. Representative data from three different experiments are presented. (B) Cells were treated with $30 \mu \mathrm{M}$ FR or $2 \mathrm{mM} \mathrm{NAC}$ for $24 \mathrm{~h}$, alone or in combination, and analyzed by flow cytometry. Representative results of three different experiments are presented. (C) Cells were pretreated with $25 \mu \mathrm{M}$ pan-caspase inhibitor z-VAD-FMK (z-VAD), $20 \mu \mathrm{M}$ caspase-9 inhibitor z-LEHD-FMK (Cas9-inhibitor), or $50 \mu \mathrm{M}$ caspase-8 inhibitor z-IETD-FMK (Cas8-inhibitor) for $1 \mathrm{~h}$ before the addition of $30 \mu \mathrm{M}$ FR. Cells were incubated for another $24 \mathrm{~h}$ and the proportion of subdiploid cells was analyzed by FACScan. ${ }^{*} \mathrm{P}<0.05 \mathrm{vs}$. FR alone. (D) Cells were preincubated with $50 \mu \mathrm{M}$ caspase-8 inhibitor z-IETD-FMK (Cas8-inhibitor) for $1 \mathrm{~h}$ prior to addition of $30 \mu \mathrm{M}$ FR and incubation for an additional $24 \mathrm{~h}$. Cell lysates were analyzed by Western blotting with antibodies against caspase-7, PARP, and actin (loading control). Images representative of the results of three different experiments are presented.

NAC did not significantly reverse FR-induced apoptosis in MCF-7 cells (Fig. 5B), indicating that ROS is not essential for FR-induced apoptosis. We next examined caspase activation during FR-induced cell death of MCF-7 cells. Addition of the pan-caspase inhibitor z-VAD-FMK or the caspase-8 inhibitor z-IETD-FMK significantly blocked the accumulation of a sub-diploid fraction in FR-treated cells but treatment with caspase-9 inhibitor z-LEHD-FMK did not (Fig. 5C). As expected, the caspase- 8 inhibitor suppressed the cleavage of the effector caspase-7 and PARP in caspase 3-deficient MCF-7 cells (25), consistent with the caspase-8-dependence of apoptosis in FR-treated cells (Fig. 5D).

\section{Discussion}

Our present study showed that FR122047 (FR), a COX-1 inhibitor induced significant cell growth arrest and apoptosis in breast cancer MCF-7 cells. Non-steroidal anti-inflammatory drugs (NSAIDs) inhibit the enzyme cyclooxygenase (COX) which convert arachidonic acid to prostaglandins (PGs). Since COXs are known to be highly expressed in tumors and to augment tumorigenesis, a number of studies have concentrated on investigating the possibility of using COX inhibitors for the prevention or treatment of cancer. Therefore, inhibition of PGs formation explain part of the anti-cancer effect of NSAIDs. Some studies have reported that inhibition of cell growth caused by treatment with a COX-2 inhibitor was reversed by addition of PGs $(26,27)$. However, several lines of evidence suggest that NSAIDs could also regulate signal pathways through COX-independent mechanisms. For example, NSAIDs lessened cell survival in COX-deficient cell lines such as HCT-15 colon cancer cell line and C33A cervical cancer cell line $(28,29)$ and have also been reported to induce anti-inflammatory effects and apoptosis through various signaling pathways independently of COXs inhibition (30-32). FR122047, a COX-1 inhibitor induced apoptosis in MCF-7 breast cancer cells by a mechanism independent of its ability to suppress PGs synthesis because exogenous $\mathrm{PGE}_{2}$ had no effect on FR122047-induced apoptosis in MCF-7 cells (data not shown).

Celecoxib and other NSAIDs showed that drug-induced apoptosis could be caused through intrinsic pathway by cytochrome c release from mitochondria and activation of caspase-9 as well as extrinsic pathway by activation of caspase-8 (34-36). FR122047-treated MCF-7 cells exhibited a rapid down-regulation of $\mathrm{Bcl}-2$, resulting in an increase in the Bax/Bcl-2 ratio. We also observed early apoptotic event, i.e., mitochondrial cytochrome c release, indicative of a wellestablished intrinsic apoptotic pathway in FR122047-treated MCF-7 cells (Fig. 3). Based on these observations, we proposed that caspase- 9 could be involved in the mechanism of FR-induced cell death. Treatment of the caspase-9 inhibitor was unable to suppress, but rather enhanced FRinduced cell death, indicating that caspase- 9 might be involved in another pathway specifically manipulating the typical apoptotic signaling pathway. However, additional experiments are required to analytically investigate this possibility and currently underway. 
Activation of extracellular signal-regulated kinase $1 / 2$ (ERK1/2) has been shown to incite apoptosis of HaCaT keratinocytes (33). Although FR122047 treatment induced activation of ERK1/2 in MCF-7 cells, an inhibitor of ERK1/2 activation failed to protect FR122047-induced cell death (data not shown), suggesting that the ERK1/2 may not be involved in FR122047-caused apoptosis in MCF-7 cells.

In summary, the present study showed that treatment of breast cancer MCF-7 cells with the NSAID FR122047 could lead to cell growth arrest and induction of caspase 8mediated apoptosis independent of reactive oxygen species (ROS) production. Our data suggest that the NSAID FR122047 may have an anti-cancer potential in breast cancer.

\section{Acknowledgements}

This study was supported in part by Basic Science Research Program through the National Research Foundation of Korea (NRF) funded by the Ministry of Education, Science and Technology (No. 2009-0083694 (No. R01-2007-000-20425-0) and No. 2009-0062910) and a grant of Korea Health 21 R\&D Project, Ministry for Health, Welfare and Family Affairs, Republic of Korea (A08-4065). We acknowledge a graduate fellowship provided by the Ministry of Education and Human Resources Development through the Brain Korea 21 project, Republic of Korea.

\section{References}

1. Briegel $\mathrm{KJ}$ : Embryonic transcription factors in human breast cancer. IUBMB Life 58: 123-132, 2006.

2. Vane JR, Bakhle YS and Botting RM: Cyclooxygenases 1 and 2. Annu Rev Pharmacol Toxicol 38: 97-120, 1998.

3. Baek SJ and Eling TE: Changes in gene expression contribute to cancer prevention by COX inhibitors. Prog Lipid Res 45: $1-16,2006$.

4. Liu XH and Rose DP: Differential expression and regulation of cyclooxygenase- 1 and -2 in two human breast cancer cell lines. Cancer Res 56: 5125-5127, 1996.

5. Half E, Tang XM, Gwyn K, Sahin A, Wathen K and Sinicrope FA: Cyclooxygenase-2 expression in human breast cancers and adjacent ductal carcinoma in situ. Cancer Res 62: 1676-1681, 2002.

6. Ranger GS, Thomas V, Jewell A and Mokbel K: Elevated cyclooxygenase- 2 expression correlates with distant metastases in breast cancer. Anticancer Res 24: 2349-2351, 2004.

7. Ristimaki A, Sivula A, Lundin J, et al: Prognostic significance of elevated cyclooxygenase-2 expression in breast cancer. Cancer Res 62: 632-635, 2002.

8. Mazhar D, Ang R and Waxman J: COX inhibitors and breast cancer. Br J Cancer 94: 346-350, 2006.

9. Kundu N and Fulton AM: Selective cyclooxygenase (COX)-1 or COX-2 inhibitors control metastatic disease in a murine model of breast cancer. Cancer Res 62: 2343-2346, 2002.

10. Lupulescu A: Prostaglandins, their inhibitors and cancer Prostaglandins Leukot Essent Fatty Acids 54: 83-94, 1996.

11. Harris RE, Namboodiri K, Stellman SD and Wynder EL: Breast cancer and NSAID use: heterogeneity of effect in a case-control study. Prev Med 24: 119-120, 1995.

12. Harris RE, Chlebowski RT, Jackson RD, et al: Breast cancer and non-steroidal anti-inflammatory drugs: prospective results from the Women's Health Initiative. Cancer Res 63: 6096-6101, 2003.

13. Grosch S, Tegeder I, Niederberger E, Brautigam L and Geisslinger G: COX-2 independent induction of cell cycle arrest and apoptosis in colon cancer cells by the selective COX-2 inhibitor celecoxib. FASEB J 15: 2742-2744, 2001.

14. Castano E, Dalmau M, Barragan M, Pueyo G, Bartrons R and Gil J: Aspirin induces cell death and caspase-dependent phosphatidylserine externalization in HT-29 human colon adenocarcinoma cells. Br J Cancer 81: 294-299, 1999.
15. Abraham MC and Shaham S: Death without caspases, caspases without death. Trends Cell Biol 14: 184-193, 2004.

16. Schultz DR and Harrington WJ Jr: Apoptosis: programmed cell death at a molecular level. Semin Arthritis Rheum 32: 345-369, 2003.

17. Ochi T, Motoyama Y and Goto T: The analgesic effect profile of FR122047, a selective cyclooxygenase-1 inhibitor, in chemical nociceptive models. Eur J Pharmacol 391: 49-54, 2000.

18. Ochi T and Goto T: Differential effect of FR122047, a selective cyclooxygenase-1 inhibitor, in rat chronic models of arthritis. $\mathrm{Br}$ J Pharmacol 135: 782-788, 2002.

19. Blomme EA, Chinn KS, Hardy MM, et al: Selective cyclooxygenase- 2 inhibition does not affect the healing of cutaneous full-thickness incisional wounds in SKH-1 mice. Br J Dermatol 148: 211-223, 2003.

20. Tripp CS, Blomme EA, Chinn KS, Hardy MM, LaCelle P and Pentland AP: Epidermal COX-2 induction following ultraviolet irradiation: suggested mechanism for the role of COX-2 inhibition in photoprotection. J Invest Dermatol 121: 853-861, 2003.

21. Kim BW, Lee ER, Min HM, et al: Sustained ERK activation is involved in the kaempferol-induced apoptosis of breast cancer cells and is more evident under 3-D culture condition. Cancer Biol Ther 7: 1080-1089, 2008.

22. Jo SH, Son MK, Koh HJ, et al: Control of mitochondrial redox balance and cellular defense against oxidative damage by mitochondrial $\mathrm{NADP}^{+}$-dependent isocitrate dehydrogenase. J Biol Chem 276: 16168-16176, 2001.

23. Salomons GS, Brady HJ, Verwijs-Janssen M, et al: The Bax alpha:Bcl-2 ratio modulates the response to dexamethasone in leukaemic cells and is highly variable in childhood acute leukaemia. Int J Cancer 71: 959-965, 1997.

24. Zhang L, Yu J, Park BH, Kinzler KW and Vogelstein B: Role of BAX in the apoptotic response to anticancer agents. Science 290: 989-992, 2000.

25. Janicke RU, Sprengart ML, Wati MR and Porter AG: Caspase-3 is required for DNA fragmentation and morphological changes associated with apoptosis. J Biol Chem 273: 9357-9360, 1998.

26. Sheng H, Shao J, Morrow JD, Beauchamp RD and DuBois RN: Modulation of apoptosis and Bcl-2 expression by prostaglandin E2 in human colon cancer cells. Cancer Res 58: 362-366, 1998.

27. Lanza-Jacoby S, Dicker AP, Miller S, et al: Cyclooxygenase (COX)-2-dependent effects of the inhibitor SC236 when combined with ionizing radiation in mammary tumor cells derived from HER-2/neu mice. Mol Cancer Ther 3: 417-424, 2004.

28. Hanif R, Pittas A, Feng Y, et al: Effects of non-steroidal anti-inflammatory drugs on proliferation and on induction of apoptosis in colon cancer cells by a prostaglandin-independent pathway. Biochem Pharmacol 52: 237-245, 1996.

29. Kim SH, Song SH, Kim SG, et al: Celecoxib induces apoptosis in cervical cancer cells independent of cyclooxygenase using NF-kappaB as a possible target. J Cancer Res Clin Oncol 130: 551-560, 2004.

30. McCracken JD, Wechter WJ, Liu Y, et al: Antiproliferative effects of the enantiomers of flurbiprofen. J Clin Pharmacol 36: 540-545, 1996.

31. Zhang X, Morham SG, Langenbach R and Young DA: Malignant transformation and antineoplastic actions of nonsteroidal antiinflammatory drugs (NSAIDs) on cyclooxygenasenull embryo fibroblasts. J Exp Med 190: 451-459, 1999.

32. Shiff SJ, Qiao L, Tsai LL and Rigas B: Sulindac sulfide, an aspirin-like compound, inhibits proliferation, causes cell cycle quiescence, and induces apoptosis in HT-29 colon adenocarcinoma cells. J Clin Invest 96: 491-503, 1995.

33. Lee ER, Kang YJ, Kim JH, Lee HT and Cho SG: Modulation of apoptosis in HaCaT keratinocytes via differential regulation of ERK signaling pathway by flavonoids. J Biol Chem 280: 31498-31507, 2005 .

34. Kern MA, Haugg AM, Koch AF, et al: Cyclooxygenase-2 inhibition induces apoptosis signaling via death receptors and mitochondria in hepatocellular carcinoma. Cancer Res 66: 7059-7066, 2006

35. Pique M, Barragan M, Dalmau M, Bellosillo B, Pons G and Gil J: Aspirin induces apoptosis through mitochondrial cytochrome c release. FEBS Lett 480: 193-196, 2000.

36. Bellosillo B, Pique M, Barragan M, et al: Aspirin and salicylate induce apoptosis and activation of caspases in B-cell chronic lymphocytic leukemia cells. Blood 92: 1406-1414, 1998. 